\title{
Clinical and Pathological Assessment of 82 Patients with Cardiovascular Diseases Undergoing Autopsy at the Hospital das Clínicas of the Faculdade de Medicina de Botucatu from 1988 to 1993
}

\author{
Reinaldo A yer de O liveira, Marcos A ugusto de Moraes Silva, Rubens Ramos de Andrade, \\ Mário Rubens Guimarães Montenegro
}

Botucatu, SP - Brazil

\begin{abstract}
Objective - To evaluated the clinical diagnostic, efficiency for basic death causes in patients dying of circulatory disease and de relative frequency of those diseases.
\end{abstract}

Methods - Analysis of medical record data of $82 \mathrm{pa-}$ tients, ages from 16 to 84 years old (68 over 40 years old), whose died of circulatory disease and had undergone necropsy in the period from 1988 to 1993 years in the University Hospital of Medicine Faculty of Botucatu-UNESP, Br.

Results - The functional class of patients were III or $I V$, in $78 \%$, and $81.7 \%$ needed urgent hospitalization. By the clinical judgment the death were by ischemic heart disease in 32 (21 acute myocardial infarction), Chagas'disease in 12, valvopathy in 11, cardiomyopathy in 7, heart failure with no specification of cardiopathy in 11 and other causes in 9. At the necropsy the death cause was ischemic heart disease in 34 patients, valvopathy in 10, Chagas'disease in 10, cardiomyopathy in 5, and heart failure with no specification of cardiopathy in 2.The concordance taxes were in the same order: $94,6 \%, 90,0 \%$, $83.3 \%, 71.4 \%$ and $28.5 \%$.

Conclusion - There was a great efficiency of clinical diagnosis for death cause in a general university hospital. The ischemic heart disease were the main causes of death.

Key words - cardiovascular diseases, autopsy, epidemio$\log y$

Faculdade de Medicina de Botucatu - UNESP

Mailing address: Reinaldo Ayer de Oliveira - Faculdade de Medicina de BotucatuUNESP - Depto de Cirurgia Cardiovascular - Rua Rubião Júnior, S/N - 18618000 - Botucatu, SP, Brazil

English version by Stela Maris C. e Gandour
In most of the industrialized western countries, cardiovascular diseases, mainly ischemic heart disease, have constituted for some decades the major cause of death. In the last decades, a change in the profile of mortality of the Brazilian population has occurred. A decrease in deaths caused by infectious and parasitic diseases has occurred while a proportional increase in deaths caused by some chronic degenerative or externally caused diseases has been observed.

A publication of the Health Department ${ }^{1}$ about the relative increase in the incidence of cardiovascular diseases shows that in 1930 these diseases accounted for $11.8 \%$ of the total deaths occurring in the Brazilian capitals, and this percentage increased to $30 \%$ in 1980. In 1988, cardiovascular diseases accounted for $34 \%$ of all deaths recorded.

The pioneering study by Cortez Júnior ${ }^{2}$ about mortality and its multiple causes in the city of Botucatu in São Paulo State has shown that cardiac and cebrovascular diseases, peripheral vascular diseases, and hypertensive diseases constituted basic causes in $42.3 \%$ of the deaths assessed.

Instigated by these premises, considering the medical report essential for diagnostic formulation, and aiming to assess hospital quality, we decided to carry out this study. This hospital quality, according to Sheps ${ }^{3}$, could be assessed through the study of the rate of use of some diagnostic methods, autopsy index, anatomicopathological studies of surgical specimens, relation between preoperative and postoperative diagnoses as well as between diagnoses prior to and after death, reliability of the diagnostic methods, mean of hospitalization, etc.

Therefore, we have chosen to carry out our study in a general public and university hospital in a city in São Paulo State (Botucatu). We assessed patients with cardiovascular diseases, trying to relate frequencies of diseases and diagnostic accuracy, as a way of assessing hospital efficacy. 


\section{Methods}

In the present study we analyzed data from medical reports of patients registered at the HC-FMB and from the autopsy reports of the Department of Pathology at the FMB in the period from January ' 88 to December' 93 , which we considered our base for establishing a list of patients. We reviewed the autopsy reports in which the basic cause of death was cardiovascular disease, and we used the guidelines for filling out the death declaration as a reference ${ }^{4}$.

Information from the medical reports was examined and transferred to the research protocol, emphasizing the clinical history and the physical examination for the formulation of a clinical diagnosis, called the initial diagnosis. The definitive diagnosis was established after analyzing the medical reports for patients' outcome and laboratory test results. Diagnoses of the basic and terminal cause of death refer to data in the autopsy report, using as a reference for filling out the protocol the manual of international statistical classification of diseases, lesions, and causes of death, revised in 1975 (OMS, 1985) ${ }^{5}$.

Patients under 15 years of age were excluded as were those cases where the medical report did not provide enough and necessary information for the adequate compliance with the protocol.

The research protocol was assembled in DBase software (dBase III PLUS version 1.0 IBM/MSDOS - copyright $\odot$ Ashton-Tate 1984, 1985, 1986.), and information was processed in EPI INFO software, version 6.0.

We obtained survival curves using the Kaplan-Meier method $^{6}$, nonparametric for the survival function, and for comparison of the curves we used the log-rank test ${ }^{7}$.

We also analyzed data from the nurse section and patients' records from other clinics, which were in the medical report, to obtain greater reliability.

\section{Results}

We reviewed 103 autopsy reports of patients whose basic cause of death was cardiovascular disease. We were able to find 82 complete medical reports. At the first medical visit records, we assessed that 27 patients (32.9\%) came from the city of Botucatu; and the other patients originated from different cities. The mean follow-up time was $1.7 \pm 3.1$ years, the maximum observation time being 15 years. Patients' ages ranged from 16 to 84 years (mean of $56.8 \pm 14.8$ years). Sixty-eight patients (82.9\%) were older than 40 years. Fifty $(61.0 \%)$ patients were males and $32(39.0 \%)$ were females. In regard to occupation, $55(67.0 \%)$ patients were either retired or housewives; a significant difference existed when we compared other occupations reported.

Among all patients studied, 63 (76.8\%) reported dyspnea; $33(40.2 \%)$ reported precordialgia; $29(35.4 \%)$ reported edema; and 24 (29.3\%) palpitation. Thirty (36.6\%) patients reported a prior history of arterial hypertension, and $16(19 . \%)$ of Chagas' disease. Data concerning functional class and management at the first medical visit showed that the pa- tients sought the hospital with evident symptoms, $78.0 \%$ of these patients were in functional class III or IV. The severity of the disease justified the high rate of hospitalization $(81.7 \%)$ at the first medical visit. Table I shows the patients grouped according to the initial diagnosis.

We observed a higher concentration of patients in only 5 categories of initial diagnosis at the first medical visit.

Table II shows the distribution of patients according to the initial diagnosis of ischemic heart disease.

The diagnostic profile of the patients with ischemic heart disease arriving at the HC-FMB depicted severe conditions requiring urgent medical attention. Acute myocardial infarction was the clinical condition of $21(70.0 \%)$ patients.

Table III shows the patients distributed according to the definitive diagnoses that oriented theirfollow-up at the HC-FMB.

The patients were then followed up on the basis of the definitive diagnosis and the complementary elements corroborating this diagnosis. Comparing the initial diagnosis with the definitive diagnosis, we observed a more homogeneous distribution of the patients in regard to Chagas' disease, mitral and aortic valve diseases, heart failure, and cardiomyopathy.

Table IV shows the patients distributed according to the definitive diagnosis of ischemic heart disease. The difference between the diagnosis of the acute and the chronic form of ischemic heart disease, as already observed in the initial diagnosis, was evident.

The patients who died underwent autopsy in the de-

\begin{tabular}{|c|c|c|}
\hline \multicolumn{3}{|c|}{$\begin{array}{c}\text { Table I - Distribution of patients according to the initial } \\
\text { diagnosis of cardiovascular diseases, based on the manual } \\
\text { of international statistical classification of diseases } \\
\text { revised in } 1975\end{array}$} \\
\hline Initial diagnosis & Frequency & Percentage \\
\hline \multicolumn{3}{|l|}{ 1) Ischemic heart disease } \\
\hline$(410-414)$ & 30 & $36.5 \%$ \\
\hline 2) Heart failure (428) & 16 & $19.5 \%$ \\
\hline \multicolumn{3}{|l|}{ 3) Chagas' heart disease } \\
\hline$(086)$ & 11 & $13.4 \%$ \\
\hline $\begin{array}{l}\text { 4) Mitral and aortic valve } \\
\text { diseases }(394 / 424)\end{array}$ & 10 & $12.1 \%$ \\
\hline 5) Cardiomyopathy (425) & 7 & $8.5 \%$ \\
\hline 6) Others & 8 & $9.7 \%$ \\
\hline Total & 82 & $100.0 \%$ \\
\hline
\end{tabular}

\begin{tabular}{|c|c|c|}
\hline \multicolumn{3}{|c|}{$\begin{array}{l}\text { Table II - Distribution of patients according to the initial } \\
\text { diagnosis of ischemic heart disease, based on the manual of } \\
\text { international statistical classification of diseases revised } \\
\text { in } 1975\end{array}$} \\
\hline Ischemic heart disease & Frequency & Percentage \\
\hline 1) Acute myocardial infarction (410) & 21 & $70.0 \%$ \\
\hline 2) Chronic forms (411-414) & 9 & $30.0 \%$ \\
\hline Total & 30 & $100.0 \%$ \\
\hline
\end{tabular}


partment of pathology at the FMB. Table V shows the distribution of the patients according to the basic cause of death, and table VI shows the distribution of the patients according to the terminal cause of death.

Considering the basic cause of death, we obtained survival curves using the Kaplan-Meier method for each cardiovascular disease as follows: ischemic heart disease (410$414)$ - the mean time of life was $443.4 \pm 146.3$ days or 1.2 years; mitral and aortic valve diseases (394-395/424) - the mean time of life was $1,186.9 \pm 453.4$ days or 3.2 years; heart failure (428) - this diagnosis does not appear as a basic cause of death; cardiomyopathy (425) - the mean time of life was $508.5 \pm 234.3$ days or 1.3 years; Chagas' heart disease the mean time of life was 793.2 \pm 333 .0 days or 2.1 years.

When we compared the distribution of the patients according to the final diagnoses and the basic causes of death, we observed the following: concordance in the diagnosis of ischemic heart disease in 34 (94.4\%) patients; concordance in the diagnosis of mitral and aortic valve diseases in $10(90.9 \%)$ patients; concordance in the diagnosis of heart failure in $2(28.5 \%)$ patients and discordance in 5 $(71.5 \%)$ patients - the diagnosis of heart failure does not frequently stand out as a basic cause of death; concordance in the diagnosis of cardiomyopathy in $5(71.4 \%)$ patients and discordance in $2(28.5 \%)$ patients, whose diagnosis was ischemic heart disease; concordance in the diagnosis of Chagas' heart disease in $10(83.3 \%)$ patients and discordance in 2 patients.

\begin{tabular}{|c|c|c|}
\hline \multicolumn{3}{|c|}{$\begin{array}{l}\text { Table III - Distribution of patients according to definitive } \\
\text { diagnosis of cardiovascular diseases, based on the manual } \\
\text { of international statistical classification of diseases revised } \\
\text { in } 1975\end{array}$} \\
\hline Definitive diagnoses & Frequency & Percentage \\
\hline $\begin{array}{l}\text { 1) Ischemic heart } \\
\text { disease }(410-414)\end{array}$ & 32 & $39.0 \%$ \\
\hline $\begin{array}{l}\text { 2) Chagas' heart } \\
\text { disease }(086)\end{array}$ & 12 & $14.6 \%$ \\
\hline $\begin{array}{l}\text { 3) Mitral and aortic valve } \\
\text { diseases (394/424) }\end{array}$ & 11 & $13.4 \%$ \\
\hline 4) Heart failure (428) & 11 & $13.4 \%$ \\
\hline 5) Cardiomyopathy (425) & 7 & $8.5 \%$ \\
\hline 6) Others & 9 & $10.9 \%$ \\
\hline Total & 82 & $100.0 \%$ \\
\hline
\end{tabular}

\begin{tabular}{|c|c|c|}
\hline \multicolumn{3}{|c|}{$\begin{array}{c}\text { Table IV - Distribution of patients according to the } \\
\text { definitive diagnosis of ischemic heart disease, based on the } \\
\text { manual of international statistical classification of } \\
\text { diseases revised in } 1975\end{array}$} \\
\hline Ischemic heart disease & Frequency & Percentage \\
\hline 1) Acute myocardial infarction (410) & 21 & $65.6 \%$ \\
\hline 2) Chronic forms (411-414) & 11 & $34.3 \%$ \\
\hline Total & 32 & $100.0 \%$ \\
\hline
\end{tabular}

\begin{tabular}{|c|c|c|}
\hline \multicolumn{3}{|c|}{$\begin{array}{l}\text { Table V - Distribution of patients according to the basic cause of } \\
\text { death, based on the manual of international statistical classifica- } \\
\text { tion of diseases revised in } 1975\end{array}$} \\
\hline Basic cause of death & Frequency & Percentage \\
\hline 1) Ischemic heart disease (410-414) & 37 & $45.1 \%$ \\
\hline $\begin{array}{l}\text { 2) Mitral and aortic valve } \\
\text { diseases }(394 / 424)\end{array}$ & 16 & $19.5 \%$ \\
\hline $\begin{array}{l}\text { 3) Chagas' heart } \\
\text { disease (086) }\end{array}$ & 11 & $13.4 \%$ \\
\hline 4) Cardiomyopathy (425) & 7 & $8.5 \%$ \\
\hline 5) Others & 9 & $13.4 \%$ \\
\hline Total & 82 & $100.0 \%$ \\
\hline
\end{tabular}

\begin{tabular}{|c|c|c|}
\hline \multicolumn{3}{|c|}{$\begin{array}{c}\text { Table VI - Distribution of patients according to the terminal cause } \\
\text { of death, based on the manual of international statistical } \\
\text { classification of diseases revised in } 1975\end{array}$} \\
\hline Terminal cause of death & Frequency & Percentage \\
\hline 1) Heart failure (428) & 30 & $36.5 \%$ \\
\hline 2) Acute myocardial infarction (410) & 28 & $34.1 \%$ \\
\hline 3) Cardiac arrhythmias (427) & 8 & $9.7 \%$ \\
\hline 5) Others & 16 & $19.5 \%$ \\
\hline Total & 82 & $100 \%$ \\
\hline
\end{tabular}

\section{Discussion}

As reported in the literature, the difficulty regarding postmortem studies of individuals with cardiovascular diseases is the large variety of study methods. Despite of the difficulties, we were able to correlate the present study with other studies already published in regard to the set of diseases and their particularities.

Waller et al $^{8}$ assessed 2,007 hearts in forensic autopsies. The hearts obtained were first examined by a forensic pathologist and then reexamined in detail by a pathologist who specialized in heart diseases. Their case series consisted of $67 \%$ males and $33 \%$ females, comprising newborn infants and individuals up to 100 years of age. In 457 (22.8\%) patients, death was caused by cardiovascular diseases, among which the most common was coronary artery disease present in $18 \%$ of the individuals, followed by cardiomyopathy in $1.5 \%$ of the individuals, acute myocarditis in $0.6 \%$, and others. Acquired heart diseases occurred in 649 (32\%) patients. The most common was atherosclerosis of the coronary arteries present in $20.6 \%$ of the patients, and among these, $76 \%$ of the patients had lesions in three coronary arteries. Cardiomyopathy and heart valve diseases accounted for $3.6 \%$ of the cases. Despite methodological differences, the study by Waller et $\mathrm{al}^{8}$ emphasizes the similarities in the classification of the cardiovascular diseases observed in our study.

Leor et al ${ }^{9}$ reported that $2.6 \%$ of the patients hospitalized due to acute myocardial infarction developed cardioge- 
nic shock within the 24 hours first of admission.

Andersen et al ${ }^{10}$ reported that from 53 autopsies of patients who had died due to the first manifestation of acute myocardial infarction, $51(96 \%)$ had acute thrombosis of one coronary artery. Death was related to cardiogenic shock in $34 \%$ of the patients. Postmortem angiography depicted obstructive lesions $\geq 75 \%$ in one, two, or three vessels. Old infarcts were observed in 24 (45\%) patients despite having no prior history of acute myocardial infarction. When triple vessel lesions occurred, an old infarct could be found in $86 \%$ of the cases. The authors conclude and emphasize that coronary artery disease involving two or three vessels and old myocardial infarcts are frequently present when acute myocardial infarction occurs. These data corroborate the importance of the acute form of ischemic heart disease, which was evidenced in our study by the distribution and evolution of the patients undergoing autopsy and their cause of death.

One factor that has been studied as contributing to the terminal cause of death is cardiac rhythm and, consequently, changes in the heart conduction system.

Nicop et al ${ }^{11}$, studying 749 patients with acute myocardial infarction of the anterior ventricular wall, showed that $94(12.8 \%)$ patients had complete atrioventricular block. Comparing this group with the group of patients without block, they observed that in-hospital mortality was $24.2 \%$ for the patients with block and $6.3 \%$ for the patients without it. In our study, cardiac arrhythmia was an important terminal cause of death.

In regard to possible differences between sexes, $\mathrm{Gu}$ tierrez et al ${ }^{12}$ did not find any difference in hearts studied at autopsies in the site of myocardial infarct and the number of arteries involved. However, when correlating clinical findings, they observed that death by myocardial infarcts occurred more frequently in the acute phase and at the first episode in females. On the other hand, severe impairment of the left main coronary artery was significantly greater in males. When considering age, Fournier et al ${ }^{13}$ found that patients 40 years of age or younger accounted for $4.1 \%$ (108 out of 2,644 patients) of the patients admitted due to acute myocardial infarction. They were 102 males and 6 females. Precordial pain was present in $42.5 \%$ of the patients and previous infarction in $6.5 \%$ of the patients. In-hospital mortality was $3.7 \%$. In our study no significant difference was found between the sexes, but these data may have been underestimated due to the number of cases studied.

Factors determining in-hospital evolution of patients admitted with a diagnosis of acute myocardial infarction are many. Among these factors, Piérad et al ${ }^{14}$ stress as the most significant the following: age, previous myocardial infarction, recent infarct located at the left ventricular anterior wall, left ventricular dysfunction, residual myocardial ischemia, and coronary artery disease in more than one vessel.

The group of patients studied is the expression of the set of patients who died. They underwent postmortem examination, and the analysis of data reveals through correlation between the diagnoses a concordant or discordant process of diagnosis establishment. Concordance or discordance between the clinical diagnosis and the basic cause of death, in the context of a general, public and university hospital, expresses not only an assessment of the process of assistance and management of patients but also the quality and efficiency of the hospital.

Data regarding functional class and the management adopted show that the patients were in severe conditions. Most of them had ischemic heart disease by the time of arrival at the hospital and establishment of an initial diagnosis. The occurrence of this disease in its acute form, i.e., acute myocardial infarction, stresses the importance of an accurate initial diagnosis and immediate admittance of the patient.

In regard to the basic cause of death, the most common diagnosis was also ischemic heart disease. Heart failure did not appear as a basic cause of death because with the autopsy an anatomicopathological diagnosis of death could be established. Considering the terminal cause of death, the number of deaths due to heart failure and cardiogenic shock following myocardial infarction was significant.

Concordance between the initial diagnosis, the definitive diagnosis, and the basic cause of death was around 95\% for ischemic heart disease and around $90 \%$ for mitral and aortic valve diseases. This shows a positive assessment of the process of assistance and management of patients, and therefore of hospital efficiency, as the initial diagnosis was accurate.

\section{Acknowledgments}

We thank Drs. Ana Maria Fioravante, Liciana Vaz de Arruda Silveira Chalita, and SheilaZambello de Pinho of the Department of Biostatistics of Instituto de Biocências de Botucatu-UNESP. 


\section{References}

1. Brasil. Ministério da Saúde. Coordenação de Doenças Cardiovasculares. Doenças Cardiovasculares no Brasil. Brasília: Sistema Único de Saúde-SUS, 1993; 36 .

2. Cortez Júnior LS. Mortalidade, segundo causas múltiplas, no município de Botucatu, S.P.Campinas, 1976. 123p. Tese (Doutorado), Faculdade de Ciências Médicas, Universidade de Campinas.

3. Sheps MC. Metodos para evaluar a calidad de la atencion hospitalaria. Organización Panamericana de la Salud. El Hospital Público Tendencias e Perspectivas. Washington, 1994; 323: 67-76.

4. Laurenti R, Mello Jorge MHP. O Atestado de Óbito. São Paulo: Centro Brasileiro de Classificação das Doenças, 1994. 77p. (Série Divulgação, 1).

5. OMS. Classificação Internacional de Doenças: Manual de Classificação Estatística Internacional de Doenças, Lesões e Causas de Óbitos. São Paulo, 1985. 2v (Revisão, 1975).

6. Kaplan EL, Meier P. Nonparametric estimation from incomplete observations. J Am Stat Assoc 1958; 53: 467-81.

7. Soares JF, Colosimo EA. Métodos estatísticos na pesquisa clínica. In: Reunião Anual da Sociedade Internacional de Biometria, 40, Simpósio de Estatística Aplicada à Experimentação Agronômica, 6, 1995. Anais, Ribeirão Preto. 105p.
8. Waller BF, Catelier MJ, Clark MA, et al. Cardiac pathology in 2.007 consecutive forensic autopsies. Clin Cardiol 1992; 15: 760-5.

9. Leor J, Goldbourt U, Reicher-Reiss H, Kaplinsky E, et al. Cardiogenic shock complicating acute myocardial infartction in patients without heart failure on admission: incidence, risk factors, and outcome. SPRINT Study Group. Am J Med 1993; 94: 265-73.

10. Andersen HR, Falk, E, Nielsen D. Clinical first myocardial infarction: coronary artery disease and old infarct in 53 consecutive fatal cases from coronary care unit. Am J Cardiovasc Pathol 1989; 2: 315-9.

11. Nicop P, Gilpin E, Dittrich H, et al. Long-term outcome in patients with inferior myocardial infarction and complete atrioventricular block. J Am Coll Cardiol 1988; 12: 589-94.

12. Gutierrez PS, Higuchi ML, Moraes CF, et al. Diferenças entre homens e mulheres em casos fatais de infarto agudo do miocárdio. Estudo de 200 necropsias. Arq Bras Cardiol 1990; 54: 189-92.

13. Fournier JA, SánchezA, Quero J, etal. Myocardial infarction in men aged 40 years or less: A prospective clinical-angiographic study. Clin Cardiol 1996; 19: 631-6.

14. Piérad LA, Dubois C, Albert A, et al. Prediction of mortality after myocardial infarction by simple clinical variables recorded during hospitalizacion. Clin Cardiol 1989; 12: 500-4. 